\title{
Progresso da brusone nas folhas e panículas de genótipos de arroz de terras altas
}

\author{
Vanda M ariaA ngeli M alavoltaㄱ, L uiz Ernesto Azzini ${ }^{1}$, Cândido Ricardo. Bastos ${ }^{1}$, \\ $M$ arcus Vinicius Salomon ${ }^{1,2}$, J airo Lopes de Castro ${ }^{3}$
}

\begin{abstract}
${ }^{1}$ A PTA / Instituto A gronômico, CP 28, 13001-970, Campinas, SP. E-mail: vanda@iac.sp.gov.br; ${ }^{2}$ Engenheiro A grônomo, E stagiário B olsista do CNPQ; ${ }^{3}$ A PTA / Pólo Regional de Desenvolvimento do Sudoeste Paulista, Capão B onito-SP.

Trabalho parcialmente financiado pela FA PESP

A utor para correspondência: Vanda M aria A ngeli M alavolta

Data de chegada: 31/03/2006. A ceito para publicação em: 18/12/2007
\end{abstract}

\section{RESUM O}

M alavolta, V.M .A .; A zzini, L.E.; B astos, C.R.; Salomon, M .V.; Castro, J .L. Progresso da brusone nas folhas e panículas de genótipos de arroz de terras altas. Summa Phytopathologica, v.34, n.2, p.186-188, 2008

Foram avaliados dezesseis genótipos de arroz quanto ao seu nível de resistência parcial à brusone (Pyricularia grisea). A reação dos genótipos à doença foi avaliada durante dois anos, em condições de cultivo de terras altas, no município de Capão Bonito, SP. A severidade da doença nas folhas e panículas foi determinada periodicamente, e os dados foram utilizados para traçar a curva de progresso da doença e cálculo da área sob a curva de progresso da doença para cada genótipo (A SCPD). Os resultados evidenciaram que, considerando os dois anos de avaliação, menores valores de ASCPD foram apresentados nas folhas pelas linhagens IAC 1711, IAC 1774 e IAC 1781 e pelas cultivares BRS Bonança e BRS Liderança; nas panículas, pelas linhagens IA C 1738, IAC 1774 e IAC 1781 e pelas cultivares BRS Bonança, BRS Liderança e Carisma.

Palavr as-chave adicionais: Oryza sativa, Pyricularia grisea, resistência parcial.

\section{ABSTRACT}

M alavolta, V.M .A.; A zzini, L.E.; B astos, C.R.; Salomon, M.V.; Castro, J.L. Progress of leaf and panicle blast in upland rice genotypes. Summa Phytopathologica, v.34, n.2, p.186-188, 2008

Partial resistance of sixteen rice genotypes to blast (Pyricularia grisea) was evaluated during two years under upland conditions ( $C$ apão Bonito, SP). B last severity on leaves and panicles was periodically determined and the data were used to obtain the disease progress curve for each genotype and to estimate the area under disease progress curve (AUDPC). Smaller AUDPC values were presented, considering leaf blast, by IAC 1711, IAC 1774 and IAC 1781 lines and $B R S$ Bonança and BRS Liderança cultivars; considering panicle blast, by IAC 1738, IAC 1774 and IAC 1781 lines and BRS Bonança, $B R S$ Liderança and Carisma cultivars.

A dditional keywords: Oryza sativa, Pyricularia grisea, partial resistance.

A brusone do arroz, causada pel o fungo Pyricularia grisea (C ooke) Saccardo = Pyricularia oryzaeC avara [teleomorfo Magnaporthegrisea (H ebert) B arr], é uma das doenças mais destrutivas e está amplamente disseminada em todas as regiões do mundo onde o arroz é cultivado. Essa doença ocorre endemicamente nas regiões produtoras, podendo adquirir caráter epidêmico quando as condições ambientais forem favoráveis, tanto em condições de cultivo inundado como de terras al tas. 0 emprego de cultivares resistentes tem sido o mais econômico e eficiente método de controle e/ ou manejo dessa doença, uma vez que o controle químico mediante o uso de fungicidas, embora eficiente, é limitado por condições econômicas, sociais e ambientais.

A resistência à brusone tem sido obtida através da incorporação nos materiais mel horados de genes ' maiores' , que conferem resistência completa a determinadas raças do patógeno, ou genes 'menores', que conferem resistência parcial (4). A obtenção de cultivares com resistência completa e específica às raças de P. grisea predominantes em determinada região é bastante utilizada em programas de melhoramento, pois permite regularmente o lançamento de material resistente devido à relativa facilidade com que é obtida (9). A necessidade contínua de obtenção de cultivares resistentes de arroz é devida à alta variabilidade patogênica do fungo $P$. grisea, que tem levado à rápida perda da resistência específica de cultivares, reduzindo sua vida útil a poucos anos de cultivo contínuo $(6,7)$.

A tualmente, a obtenção de cultivares com resistência parcial à brusone tem sido um dos principais objetivos dos centros de pesquisa em arroz. A principal característica da resistência parcial é a redução na taxa aparente de infecção $(4,10)$. A utilização de cultivares com resistência parcial tem sido bastante útil no manejo da brusone, embora sua eficiência varie conforme o nível desse tipo de resistência presente 
no genótipo (5). No B rasil, estudos foram realizados abordando vários aspectos da resistência parcial, incluindo determinação dos níveis de resistência parcial de diversas cultivares com base nos valores de área sob a curva de progresso da doença $(1,2,8)$.

0 presente trabalho obj etivou avaliar os níveis de resistência parcial à brusone em 16 genótipos de arroz de terras altas. Experimentos foram instalados nos anos agrícolas 2002/2003 e 2003/2004 para avaliação dos genótipos de arroz integrantes dos ensai os comparativos avançados do Programa de Melhoramento de A rroz do IAC, que incluem linhagens previamente selecionadas nos ensaios preliminares e cultivares comerciais para servirem como parâmetros comparativos. Esses ensaios destinam-se à aval iação final de linhagens elite e definem os genóti pos que deverão ser lançados como novas cultivares, servindo também como fonte de dados para a determinação do Valor de Cultivo M ínimo (VCU), necessário para o registro das novas cultivares.

Dezesseis genótipos foram avaliados em cultivo de terras altas, sob irrigação por aspersão, no Polo de D esenvolvimento Tecnológico dosA gronegócios do Sudoeste Paulista, no município de Capão B onito. São eles: IA C 201, I A C 202, BRS Bonança, Carisma, BRS Primavera, IAC 1652, IA C 1711, IA C 1732, IA C 1738, IAC 1740, IAC 1744, IAC 1774, IAC 1776, IA C 1779, IAC 1781 e BRS Liderança.

0 delineamento experimental adotado foi de blocos ao acaso, com 16 tratamentos e 4 blocos. As parcelas experimentais foram constituídas por 7 linhas de $5 \mathrm{~m}$ de comprimento, considerando-se como espaço útil para as avaliações as 5 linhas centrais, excluindo-se $0,50 \mathrm{~m}$ nas extremidades de cada linha. A adubação basal foi de 400 $\mathrm{kg} \cdot \mathrm{ha}^{-1}$ da mistura 4-14-8. Foram feitas 2 adubações nitrogenadas em cobertura, aos 40 e 60 dias pós emergência, empregando-se 20 kg de nitrogênio. ha-1.

A avaliação do desenvolvimento da brusone foi realizada nas folhas e panículas.

Nas folhas, no período compreendido entre os 35 e 85 dias após emergência no primeiro ano, e entre os 36 e 90 dias no segundo ano, foram realizadas 5 avaliações da severidade da doença, utilizando-se escala visual de 10 graus, onde foram consideradas as seguintes porcentagens de área foliar infectada: $0 ; 0,5 ; 1,0 ; 2,0 ; 4,0 ; 8,0 ; 16,0$; 32,$0 ; 64,0 ; 82,0 \%$. Foram amostrados 20 perfilhos/parcela, colhidos ao acaso, avaliando-se todas as folhas dos perfilhos. A severidade da brusone na panícula foi determinada também através de 5 avaliações, no período compreendido entre os 95 e 124 dias após emergência no primeiro ano, e entre os 108 e 146 dias no segundo ano, em 20 panículas de cada parcela através da porcentagem de área da panícula afetada, utilizando-se escala visual de 5 graus onde foram consideradas as porcentagens de 5,0; 25,0; 50,0; 75,0 e 100\% . A última avaliação foi efetuada no dia da col heita, que foi variável conforme o ciclo vegetativo de cada genótipo.

Os dados das avaliações real izadas quanto à ocorrência de brusone nas fol has e panículas foram utilizados para traçar a curva de progresso da doença para cada genótipo. A s respectivas áreas sob essas curvas (A SCPD) foram cal culadas pelo método de integração trapezoidal (3). Os valores obtidos nas avaliações realizadas em cada parcela foram submetidos à análise de variância. A comparação das médias foi feita pelo Teste de Tukey, a 5\% de probabilidade.

A presentaram ciclo mais curto nos dois anos os materiais IAC 1776, IA C 1711, IA C 1774, IAC 201 e BRS Primavera, e ciclo maislongo IAC 1740, IA C 1779, IAC 1744, IA C 1732 eBR S B onança. Os demais materiais, IA C 1738, IA C 1652, IA C 1781, BRS Liderança, Carisma e IA C 202, considerados de ciclo intermediário, apresentaram ciclo maior no primeiro ano e menor no segundo, no qual ocorreu maior déficit de água.

A severidade de brusone nas folhas foi baixa nos dois anos, atingindo valores máximos de $1 \%$ de área foliar infectada nos dois anos. Isso significa, em termos práticos, no máximo 3 lesões desenvolvidas por folha madura, ou no caso de lesões pouco

Tabela 1. Á rea sob a curva de progresso da doença (ASCPD) apresentada por folhas e panículas de dezesseis genótipos de arroz. Capão Bonito, anos agrícolas 2002/03 e 2003/2004.

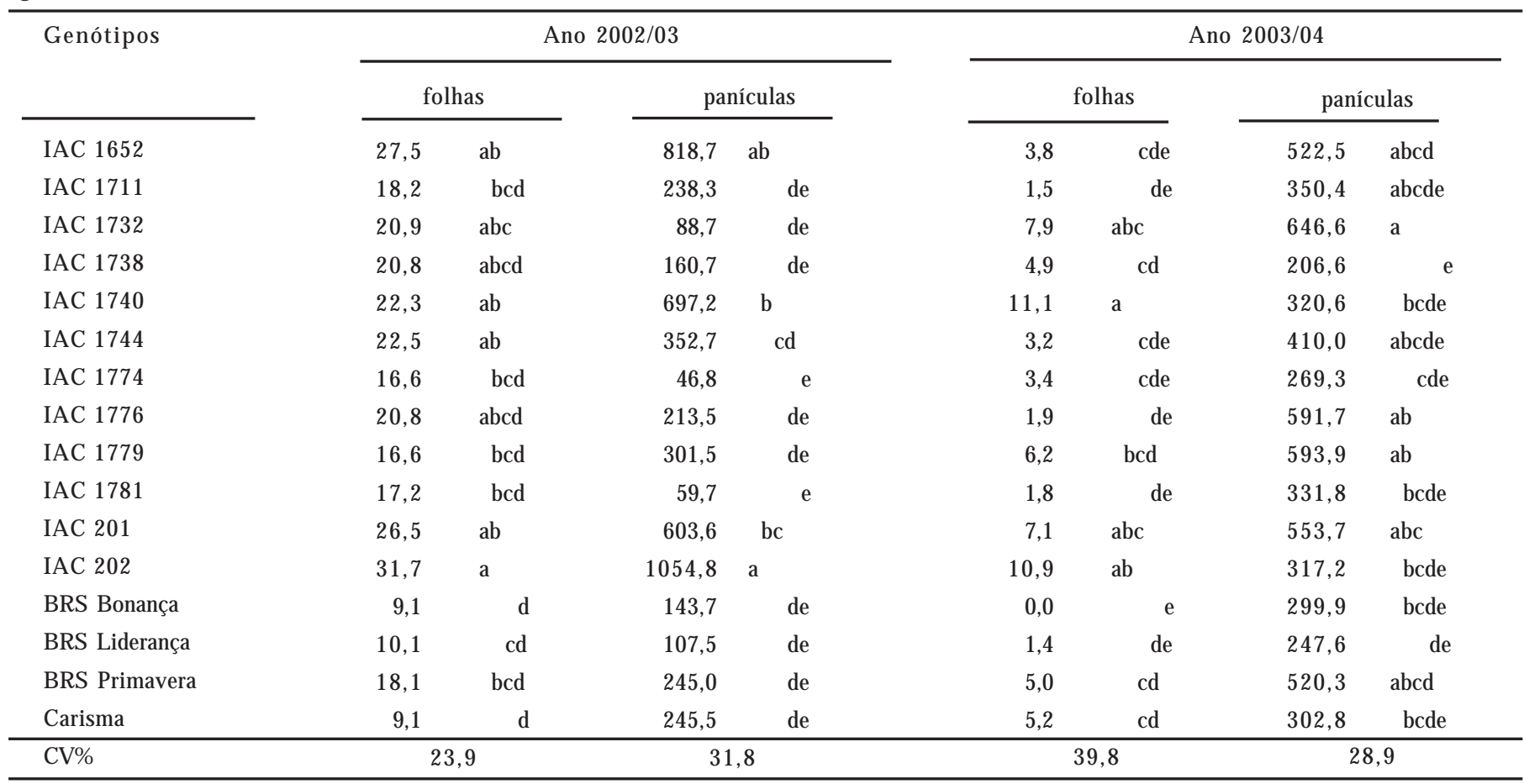

M édias seguidas da mesma letra, na mesma coluna, não diferem entre si (Tukey, 5\%). 
desenvolvidas, típicas de material com resistência parcial, cerca de 67 lesões por folha madura.

$\mathrm{N}$ as panículas, contrariamente, a infecção por brusone foi bastante severa nos dois anos, atingindo até 61,8 e $73,4 \%$ de área média de panícula infectada durante o primeiro e segundo ano, respectivamente. A severidade final de brusone foi maior no segundo ano em relação ao primeiro em 15 do total de 16 materiais avaliados. Este fato deve-se provavelmente à grande influência das condições climáticas no desenvolvimento da doença, conforme anteriormente relatado $(4,9)$.

Os valores de área sob a curva de progresso da doença (A SCPD) para os diversos genótipos estão apresentados na Tabela 1, podendose observar diferenças significativas entre os materiais nos dois anos e nas 2 variáveis avaliadas.

Os menores valores de A SCPD nas folhas, nos dois anos, foram apresentados pelas linhagens IA C 1711, IA C 1774, I A C 1781 e pelas cultivares BR S Bonança e BR S Liderança. Nas panículas, a classificação dos genóti pos apresentou semel hanças com a observada com relação à brusone foliar. Os menores ASCPD foram consistentemente apresentados por IAC 1738, IAC 1774 e IA C 1781, e cultivares BRS B onança, BRS Liderança e Carisma. Destacam-se as linhagens IA C 1774 e IA C 1781, que apresentaram tanto nas fol has quanto nas panículas, nos 2 anos de avaliação, baixos valores de A SCPD.

A s cultivares comerciais IA C 201 e IA C 202 apresentaram alguns dos maiores valores deA SCPD nas fol has e panículas nos dois anos. Esse comportamento deve-se à predominância de cultivo dessas cultivares há vários anos em todo o Estado de São Paulo, havendo grande prevalência deraças fisiológicas de Pyriculariagriseaespecíficas a elas. Essas cultivares, embora apresentassem resistência à brusone quando lançadas no mercado, tiveram essa resistência quebrada em pouco tempo. Isso reforça a necessidade da obtenção de cultivares com um bom nível de resistência parcial, que possa garantir a vida útil da cultivar com boas características agronômicas mesmo após a perda de uma provável resistência específica. As cultivares comerciais BRS B onança e Carisma, incluídas nesses experimentos como parâmetros comparativos de produção e plantadas comercialmente em outros Estados, são pouco utilizadas no Estado de São Paulo, e apresentaram comportamento resistente à brusone, provavel mente pela baixa frequência de raças fisiológicas compatíveis na região de Capão B onito.

\section{BIBLIOGRAFIA}

1. ARAÚJO, L.D.; PRABHU, A.S. Progresso da brusone nas foIhas e características agronômicas nas gerações avançadas de somaclones aromáticos da cultivar de arroz IAC 47. Fitopatologia Brasileira, Brasília, v.26, n.3, p.606-613, 2001.

2. ARAÚJO, L.D.; PRABHU, A.S. Resistência parcial à brusone em somaclones da cultivar de arroz CICA-8. Fitopatologia Brasileira, Brasília, v.29, n.4, p.394-398, 2004.

3. BERGER, R.D. The analysis of effects of control measures on the development of epidemics. In: Kranz, J. \& Rotem J. Experimental techniques in plant disease epidemiology. 1988. Springer, Heidelberg. p.137-151.

4. BONMAN, J.M. Durable resistance to rice blast disease - environmental influences. Euphytica, Wageningen, v.63,n.1-2, p.115-123, 1992.

5. BONMAN, J.M.; ESTRADA, B.A.; KIM, C.K.; RA, C.K.; LEE, E.J. A ssessment of blast disease and yield loss in susceptible and partially resistant rice cultivars in two irrigated lowland environments. Plant Disease, St. Paul, v.75, n.5, p.462. 466, 1991.

6. CORREA-VICTORIA, F.J.; ZEIGLER, R.S. Stability of parcial and complete resistance in rice to Pyricularia grisea under rainfed upland conditions in eastern Colombia. Phytopathology, St. Paul, v.85, n.9, p.977-982, 1995.

7. MALAVOLTA, V.M.A.; AMARAL, R.E.M.; ISSA, E.; CAMAR GO, O.B.A. Estabilidade da resistência à brusone em cultivares/ linhagens de arroz. Summa Phytopathologica, Jaguariúna, v. 18, n.2, p.111-117, 1992.

8. MALAVOLTA, V.M.A.; PETTINELLI JUNIOR, A.; FANTIN, G.M.; SILVA, T.M.W. Determinação de níveis de resistência parcial à brusone em cinco genótipos de arroz. Summa Phytopathologica, Jaguariúna, v.21, n.2, p.117-123, 1995.

9. OU, S.H. Rice diseases. 2 äE dição. K ew, Commonwealth Mycological Institute. 1985. 379 p.

10. VAN DER PLANK, J.E. Disease resistance in plants. A cademic Press. New York. 1968. 206 p. 